\title{
Additively manufactured penetrating warheads
}

\author{
Jérôme Limido ${ }^{1, *}$, Paul Deconinck ${ }^{3}$, Aurélien Beaucamp ${ }^{2}$,Frédéric Paintendre ${ }^{2}$, and Pierre-Louis Hereil ${ }^{3}$ \\ ${ }^{1}$ IMPETUS Afea, Grenade, France \\ ${ }^{2}$ MBDA, Le Plessis-Robinson, France \\ ${ }^{3}$ Thiot Ingénierie, Route Nationale, 46130 Puybrun, France
}

\begin{abstract}
Penetrating warheads have to both defeat thick and high strength targets and have high blast effects. Lattice structures could help to enhance blast effect and reduce the weight of the penetrators. Additive manufacture provides a method to produce this concept. This paper details a programme to evaluate the perforation performance of such a penetrator. This study implemented an approach based on the integration of virtual and physical tests. A mesoscale numerical approach based on explicit high order finite element (HOFEM) was first developed to optimize the lattice pattern. The dynamic behaviour of this material was then determined using the Split Hopkinson Pressure Bar (SHPB) technique and this was then used to fit a constitutive model in Impetus Afea Solver ${ }^{\circledR}$. The modelling of the concrete penetration of small scale warhead was based on the advanced meshless approach coupled with HOFEM. The models developed enabled the determination, simultaneously, of the homogenised behaviour of the lattice material and also the global behaviour of the penetrators during and after the penetration. Seven ballistic tests against concrete targets were performed at Thiot Ingenierie to investigate the penetration capabilities of the additively manufactured penetrating warhead concept and especially when using a lattice pattern.
\end{abstract}

\section{Introduction}

Performance of penetrating warheads is mainly evaluated based on penetration and blast/fragmentation capabilities. Traditional manufacturing processes/materials limit the design evolution and thus penetrating warhead blast performance. Additive manufacturing could make it possible to produce improved warheads.

Penetrating warhead design has to deal with 2 contradictory goals: high penetration (thick casing) and high blast effect (thin casing). A recent project has studied how to replace steel by composite tube material in order to improve blast effect capabilities while maintaining penetration performance and reducing collateral damage.

We propose here to evaluate an alternative strategy based on lattice structure materials. Indeed, recent development of additive manufacturing allows us to create a lattice structures between 2 thin plates (or cylinder). It means that actual full steel warhead could be replaced by a lattice based warhead.

Nevertheless, two linked critical points need to be studied:

- On a design point of view, an infinity of lattices can be created. Does one (or more) allow us to combine high axial strength and high fragmentation ratio in radial expansion?

- On a production point of view, what are actual limitations of additively manufactured lattice based warhead? (Material strength, geometric accuracy, cost, design, defects, etc.)

In order to answer these questions, we implemented a project under the MCM-ITP framework (The Materials and Components for Missiles, Innovation and Technology Partnership is a UK MoD and DGA sponsored research fund) involving the following topics: manufacturing, characterization and simulation. Indeed, it is not realistic to realise dynamic experiments (crash, explosion, etc.) on hundreds of lattice configurations.

Proposed research methodology can be summarized as follows:

- 3D Lattice pattern design proposals

- Transient dynamics numerical evaluation of proposed 3D lattice pattern: crash, penetration

- Manufacturing Lattice material coupons

- Dynamic characterization of coupons (Hopkinson bars)

- $\quad$ Lattice based penetrating warhead design proposal

- $\quad$ Manufacturing proposed lattice based penetrating warhead design

- $\quad$ Small scale testing (penetration)

We will focus in this paper on numerical models developed and final experimental validation based on ballistic tests.

\section{Lattice pattern numerical evaluation}


This section deals, on the one hand, with the definition of the lattice pattern which has been used during the project for the mechanical characterization tests but also for the penetration ones. On the other hand, it deals with the definition of the specimens used for the quasi-static and the dynamic mechanical characterization tests.

We evaluated two classic lattice patterns: diamond and octet truss (see Figure 1).

The thickness of the beams has been arbitrarily defined with the aim of obtaining an acceptable apparent density of about 0.5 (reduction in terms of mass).
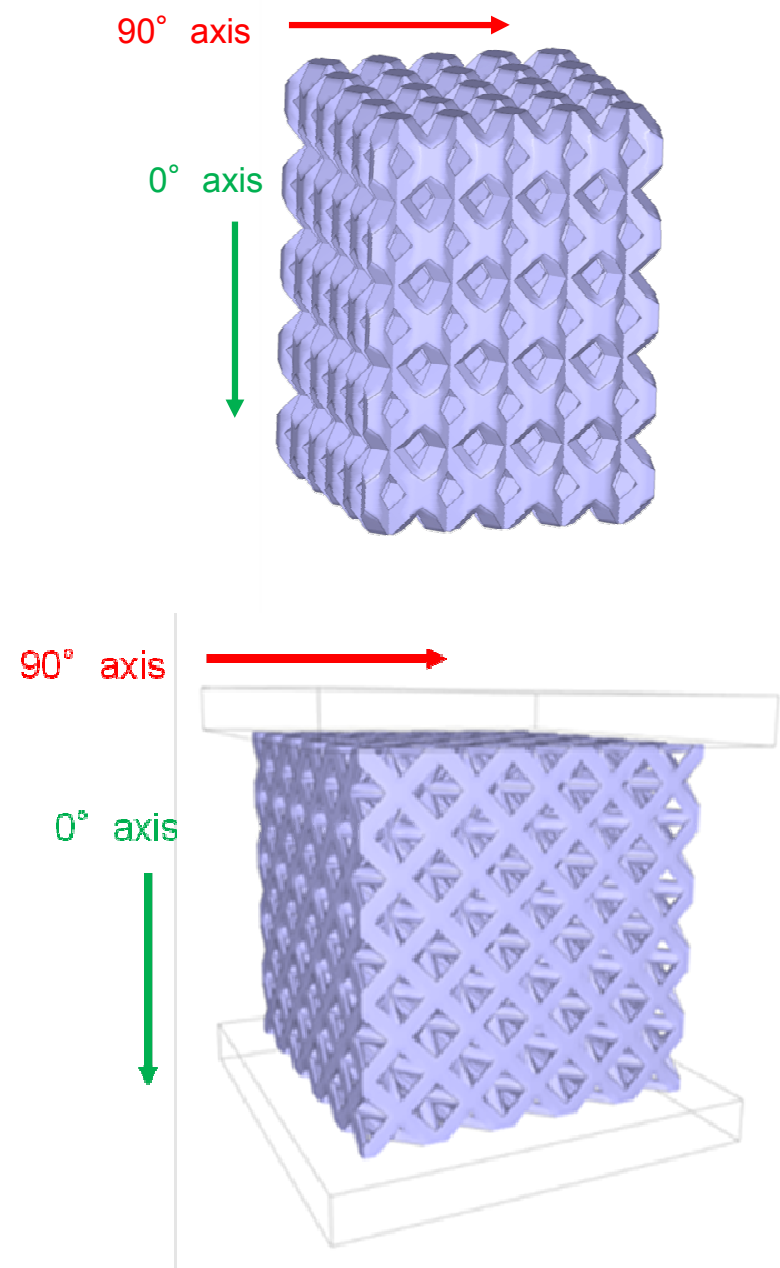

Fig. 1. "Diamond" (top) and Octet Truss (bottom) $5 \times 5 \times 5$ unit cells.

A numerical evaluation of these lattice unit cells and Representative Elementary Volume (REV) based on a $5 \times 5 \times 5$ unit cells has been performed with IMPETUS Solver $^{\circledR}$ framework. This is in order to determine its behaviour under quasi-static and dynamic loading.

The numerical model is based on 3rd order elements with full and auto-contact (see [1]). A displacement is imposed to the top of the REV. This displacement leads to a 0.3 max engineering strain $(30 \%)$.

A simplified Johnson-Cook material model was used and the initial material defined was a $316 \mathrm{~L}$ Stainless Steel.

The Diamond lattice REV shows a stable deformation regime without local buckling but it exhibits a strong anisotropy at $0^{\circ}$ and $90^{\circ}$ which is not compatible with the targeted use, within a warhead casing. Indeed, warhead casings or bodies present basically axisymmetric geometries.

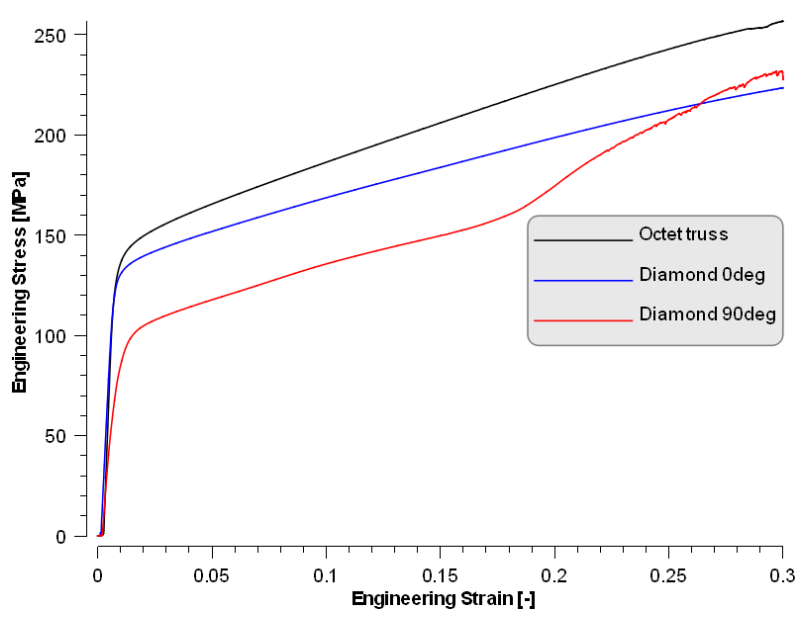

Fig. 2. Engineering stress-strain curves of the octet truss vs diamond lattice.

Moreover, for the $90^{\circ}$ compression, strong nonlinearity has been highlighted. This is also a problem as it is difficult to control.

The Octet Truss lattice is, by construction, quasiisotropic and generates various direction trusses that make it compatible with cylindrical geometry (more than the diamond one).

The retained dimensions of the unit cell are:

- Truss length: $2.18 \mathrm{~mm}$

- Unit cell edge length: $3.08 \mathrm{~mm}$

- Truss diameter: $0.74 \mathrm{~mm} \rightarrow$ relative density of 0.5

Octet truss lattice based coupons reach higher apparent yield stress and a more linear hardening compared to the diamond lattice.

To conclude, thanks to the previous observations, the octet truss lattice is a better candidate than the diamond one for penetrating warhead applications. Nevertheless, the apparent yield stress is quite low as the material used is a $316 \mathrm{~L}$, it therefore does not seem to be well suited for a penetrating warhead. We propose in the following an alternative material for manufacturing, stainless steel $17-4 \mathrm{PH}$.

\section{Small scale penetrator}

\subsection{Geometric definition}

The definition of the small scale penetrators is the key point as those penetrators are going to be used for firing tests to demonstrate the feasibility, in terms of mechanical strength and performance, of using lattices within a penetrating warhead casing.

The small scale penetrating warhead definition is based on an existing warhead concept which has been designed for penetrating purposes, called here reference penetrator. 
A reduced scaling factor is applied to the different dimensions of the warhead in order to fit with the Thiot Ingénierie facility (tube caliber and light-gas gun performances).

A representation of the geometry is given in Figure 3.

The Reference Small Scale Penetrator (RSSP) is made of solid material.

The proposed concept, based on the reference one, replaces a part of the cylindrical solid material warhead casing by an outer skin /lattice material / inner skin sandwich. This specific design is developed to insure mechanical strength and at the same time to reduce confinement effects to improve blast capabilities. As a start, a geometry is proposed, it is shown in Figure 3.

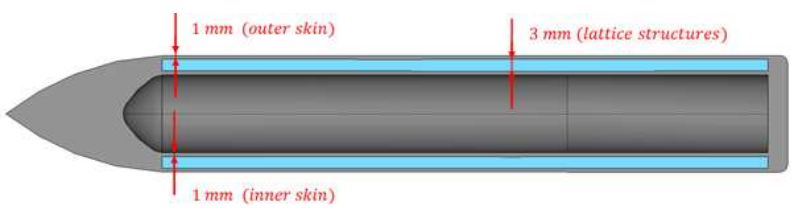

Fig. 3. Lattice based small scale penetrator geometry.

\subsection{Manufacturing}

The manufacturing department of MBDA France, produced these $17-4 \mathrm{PH}$ parts and realised a heattreatment on the specimens in order to get the best mechanical properties. A total of 15 warheads have been manufactured.

A cut view of the projectiles, reference and lattice based, is provided in following figure.

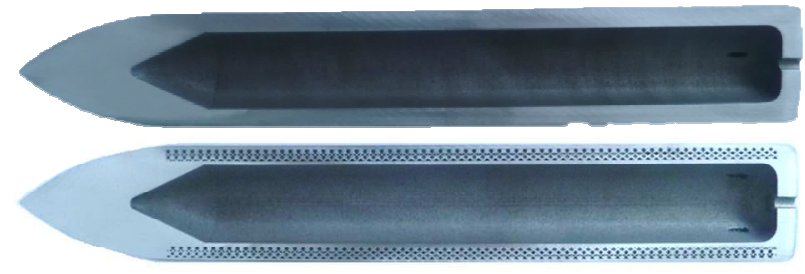

Fig. 4. Reference small scale penetrator (top) and lattice based small scale penetrator (bottom) - Cut view.

The mass saving is very important and promising. It shows a mass reduction of about $15 \%$. Theoretically, based on the numerical model, this mass reduction was about $30 \%$. The difference comes probably from the fact that not all the metal powder included within the lattice structures is eliminated.

\section{Numerical model and firing test design}

\subsection{Penetrator finite element model}

The warhead numerical model is based on 3rd order FE. This formulation leads to a good accuracy in bending and for local gradients for example plastic deformation.

The model is decomposed into two parts:

- $\quad$ the full solid 17-4PH material

\section{- $\quad$ the lattice material made of $17-4 \mathrm{PH}$}

Regarding the modelling of the lattice material part, it was not realistic to try to mimic the real $3 \mathrm{D}$ lattice structures. Indeed, the octet truss unit cell is a really complex structure and trying to model all the 3D lattice structures is far too complex. Moreover, it would have led to a huge number of FE which could have impacted the time calculation.

That is why an equivalent lattice material model is proposed. It is based on numerically identified stressstrain curve for octet truss lattice, Figure 2. The lattice material model is defined as a tabulated evolution of the yield stress, no stress/strain rate effect is considered as a first assumption.

This assumption is supported by a study [2] that shows very low effect of intrinsic strain rate sensitivity and large inertia effect. Furthermore, the work done in [3] shows a limited influence of strain rate on octet truss lattice structures: the flow stress is increased by around 10 to $20 \%$ between the quasi-static $\left(10^{-3} \mathrm{~s}^{-1}\right)$ and the dynamic regime $\left(10^{3} \mathrm{~s}^{-1}\right)$. Finally, the first aim of this model is to assess the relevance of the proposed design and its mechanical strength.

\subsection{Concrete model}

This section focuses on concrete modelling. The defined concrete is a standard strength concrete type with a compressive strength between $40 \mathrm{MPa}$ and $50 \mathrm{MPa}$.

Two approaches were evaluated during the project for concrete modelling:

- High order FE with conversion to discrete elements for too largely deformed elements Gamma-SPH [4]

The first approach provides direct alternative to classic reduced integration explicit $\mathrm{FE}$ with erosion criterion. Most of the time, the erosion control parameters are difficult to define and depend on the problem and the way it is modelled. High order FE, called HOFEM, allows larger deformation before erosion (numerical "artifice") and when an element is removed from the calculation, discrete elements are created in order to conserve the mass.

The Gamma-SPH is a 3D stable meshless method, full details and explanation of this method are provided in the report [4]. This approach enables us to bypass the erosion and/or conversion into discrete elements, it is a good alternative to classic FE methods.

It has been decided to use classical HolmquistJohnson-Cook (HJC) material model [5]. The main benefit of this model is that all its parameters are available in open literature as shown in [5].

Indeed, the concrete material model has to be validated in order to get the most accurate results in terms of exit velocity of the penetrators but also in terms of material behavior (failure, crack, damage). The validation is based on experiments carried out by Hansson Håkan [6].

IMPETUS Afea solver ${ }^{\circledR}$ model predicts an exit velocity about $149 \mathrm{~m} / \mathrm{s}$, which represents an error of $6.5 \%$ compared to the experiment. Global behavior of the 
concrete material is correctly reproduced by the model as well as the accuracy of the exit velocity. The approach is then considered as validated and is applied to the design and prediction of the firing tests.

A visual comparison between experiments and numerical model based on 25 million Gamma SPH cells model is made in Figure 5.
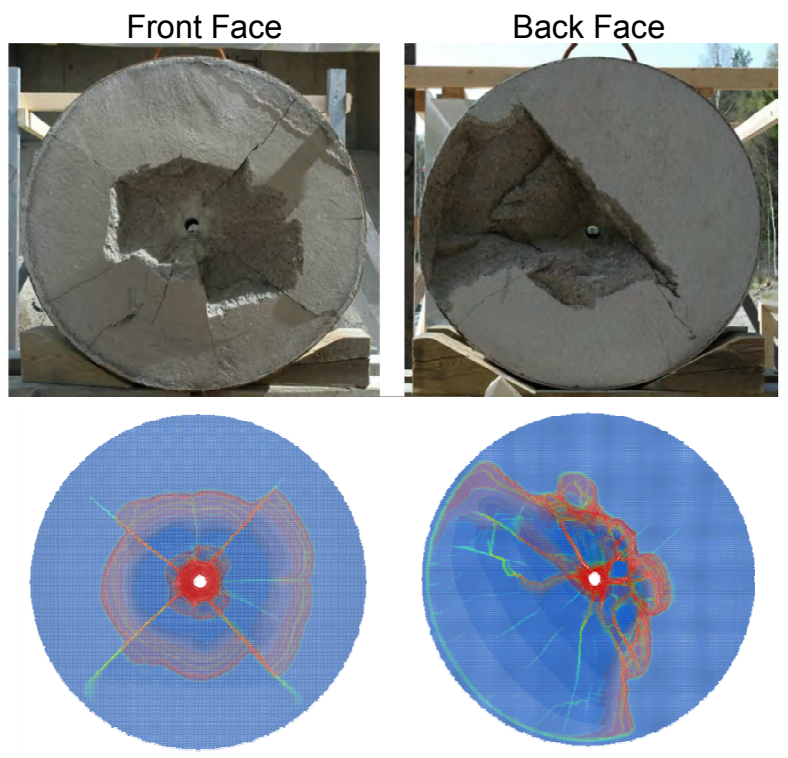

Fig. 5. Comparison of the numerical and experimental results Front and back face of the concrete target - Bottom: damage visualisation and Top: experiment visualisation [6].

\subsection{Firing test design}

The design of the firing tests is made using the numerical approach developed and described in the previous section. The firing tests design is fully based on predictive simulations (see §3.1-3.2). Several iterations and simulations were made to reach the final configurations to be tested. Predicted behaviours are summarized in Table 1.

Figure 6 shows an example of penetration model visualization. This model is related to configuration $\mathrm{A}$.

Table 1. Firing test predicted behaviour.

\begin{tabular}{|c|c|c|c|c|c|}
\hline Config & $\begin{array}{l}\text { Imp act } \\
\text { velocity } \\
\text { (m/s) }\end{array}$ & $\begin{array}{c}\text { Target } \\
\text { definition }\end{array}$ & $\begin{array}{c}\text { Angle } \\
\text { (9) }\end{array}$ & $\begin{array}{c}\text { Extt } \\
\text { velocity } \\
(\mathbf{m} / \mathrm{g})\end{array}$ & $\begin{array}{l}\text { Penetrator } \\
\text { failure }\end{array}$ \\
\hline A & 350 & $\begin{array}{l}\text { Concrete } \\
200 \mathrm{~mm}\end{array}$ & 0 & 120 & No \\
\hline B & 350 & $\begin{array}{l}\text { Concrete } \\
200 \mathrm{~mm}\end{array}$ & 15 & 90 & No \\
\hline C & 450 & $\begin{array}{c}\text { Concrete } \\
200 \mathrm{~mm}+ \\
200 \mathrm{~mm}\end{array}$ & 0 & 0 & No \\
\hline D & 550 & $\begin{array}{c}\text { Concrete } \\
200 \mathrm{~mm}+ \\
200 \mathrm{~mm}\end{array}$ & 0 & $<50$ & No \\
\hline $\mathbf{E}$ & 700 & $\begin{array}{c}\text { Steel/ } \\
\text { Concrete / } \\
\text { Steel / } \\
\text { Concrete } \\
10 \mathrm{~mm} / \\
200 \mathrm{~mm} / \\
10 \mathrm{~mm} / \\
200 \mathrm{~mm}\end{array}$ & 0 & $\sim 100$ & Yes \\
\hline
\end{tabular}
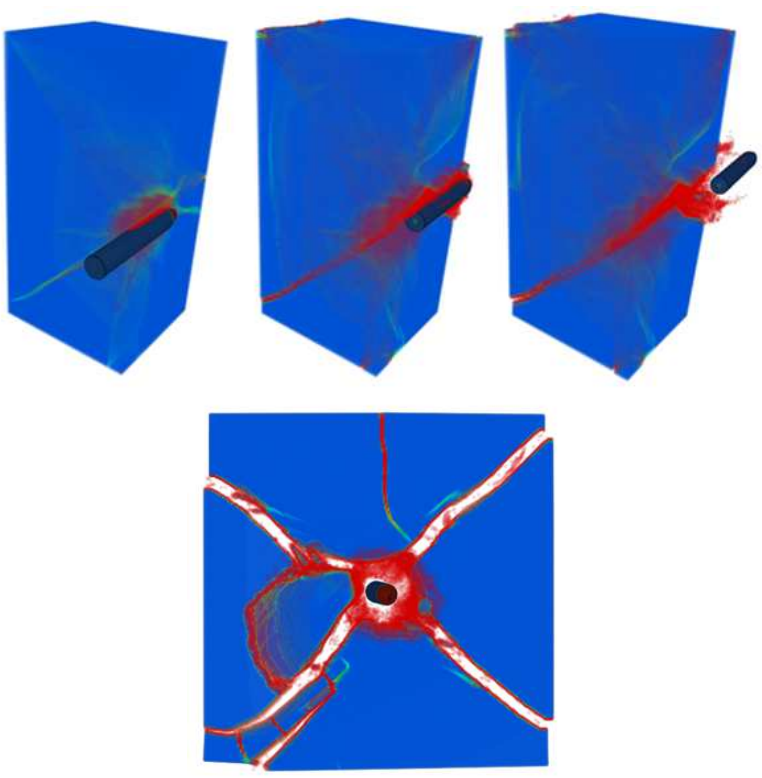

Fig. 6. Configuration A, Penetration half section views (top) and back face damage (bottom).

\section{Small scale penetrator firing tests}

This section focuses on the experimental firing tests performed in THIOT Ingénierie Shock Physics laboratory. We will focus on configuration A and E (see Table 1).

\subsection{Experimental configuration}

The configuration described in Figure 7 is positioned within the impact chamber of the VULCAIN doublestage light-gas gun.

A polycarbonate sabot is bonded around the penetrator in order to ensure the airtightness with the tube of the gas gun. Projectile velocity is measured $180 \mathrm{~mm}$ before the impact using two optical barriers. Those two barriers are connected to a numerical oscilloscope. The error given by the standardisation certificate is less than $1 \%$.

Two x-rays are positioned in front of the target in order to check there is no tilt, difference between the longitudinal axis of the penetrator and the launching axis.

The concrete targets have been casted in a $450 \times 450$ x $200 \mathrm{~mm}^{3}$ mould. The granulometry is estimated at around $8 \mathrm{~mm}$.

It is really important to bear in mind that the scale reduction is not necessarily applied to the concrete granulometry but if a comparison is made between the projectile diameter and the granulometry the ratio can be important. In this case, about 0.2 , it has to be taken into account while analysing the results.

The velocity of the back face of the target is measured with a heterodyne laser velocimeter. The projectiles are recovered in a soft recovery box full of low density materials (wood, foam, etc.). 


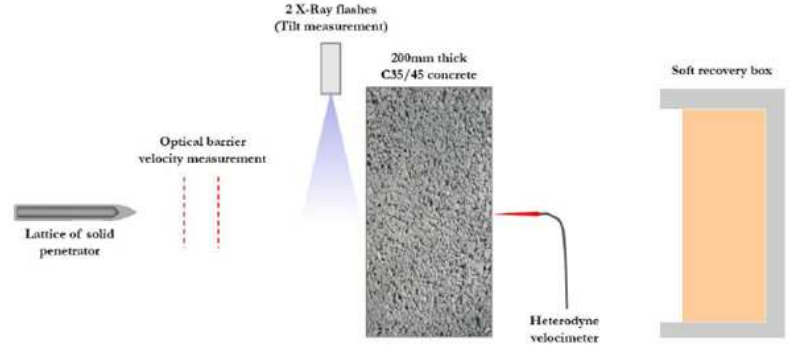

Fig. 7. Experimental configuration.

\subsection{Configuration A results}

The first test was performed to adjust as well as possible the impact velocity to be as close as possible to the targeted one, $350 \mathrm{~m} / \mathrm{s}$. It was also a good way to control the measurement tools.

This feasibility impact test has been realised with a lattice penetrator from MBDA and with a concrete target oriented at $0^{\circ}$ (normal impact). The perforation capability of the penetrator was demonstrated with this test, see the following figures.
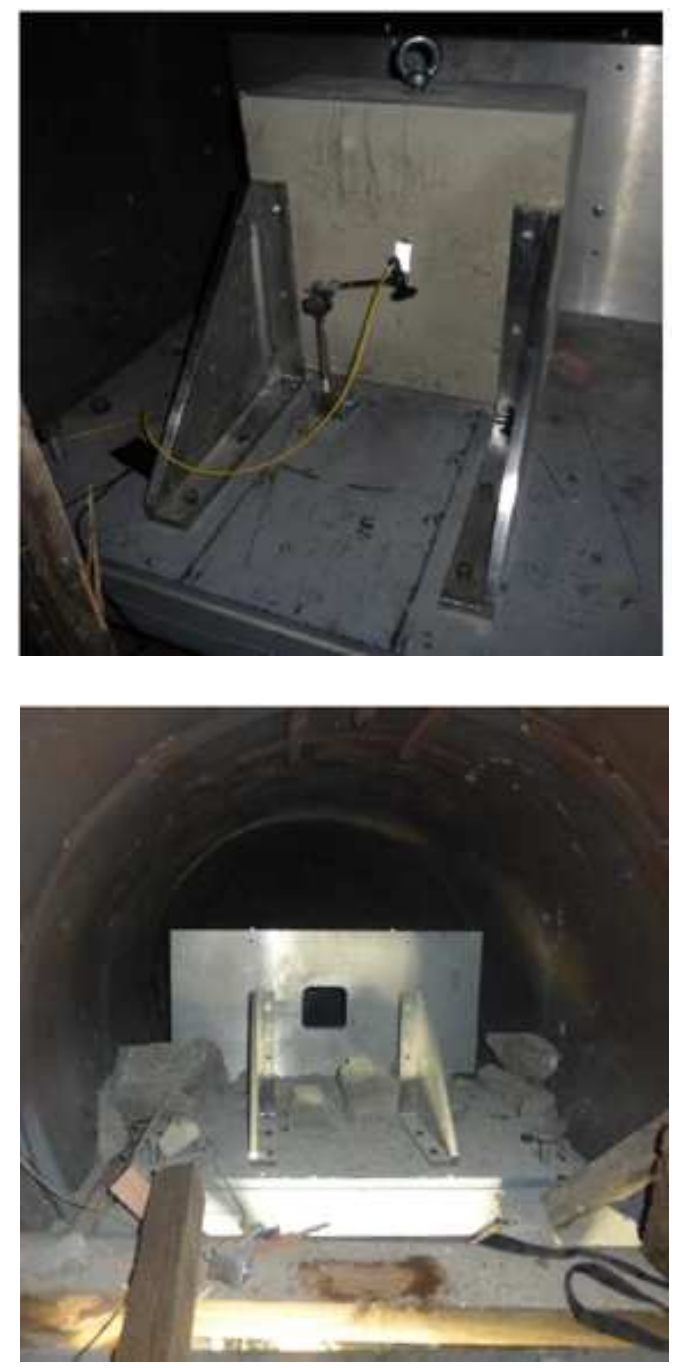

Fig. 8. Configuration A, Views of the targets before firing (top) and after firing (bottom).

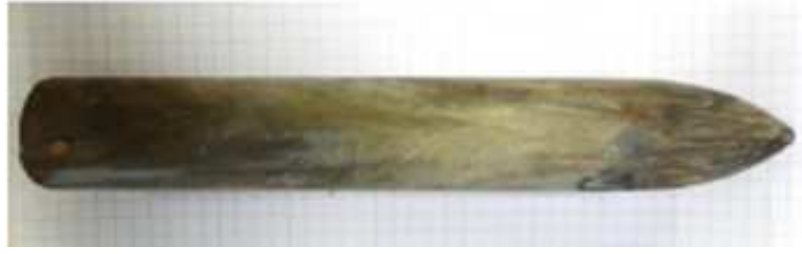

Fig. 9. Configuration A, Post-test penetrator view.

\subsection{Configuration E results}

The objective of this test was to reach the mechanical limits of the lattice based penetrator An impact velocity of $723 \mathrm{~m} / \mathrm{s}$ has been reached with the gas gun. Two steel plates (E36) have been intercalated between the concrete targets in order to intensify the load undergone by the penetrator.

The projectile fully perforated the four targets (see Figure 10) but it broke in two parts in a region close to the beginning of the lattice structures (see Figure 11).

The homogeneity of the hole within the steel plates, $32 \mathrm{~mm}$ each, shows the failure of the projectile occurred during the perforation of the second concrete target, the last one.

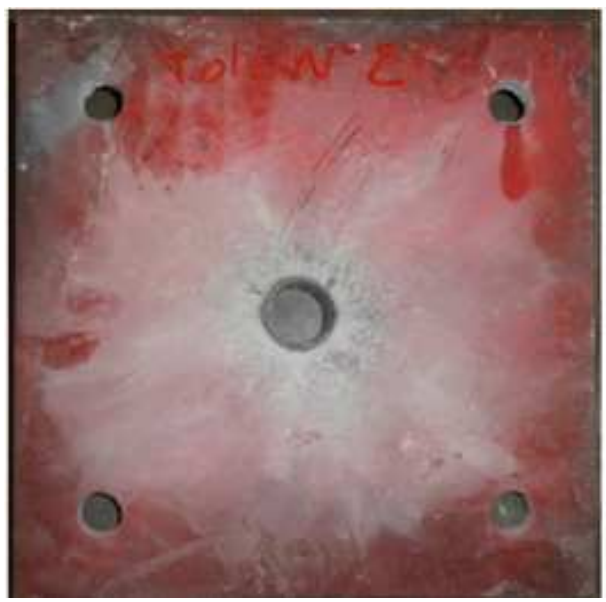

Fig. 10. Configuration E, Second steel plane perforation.

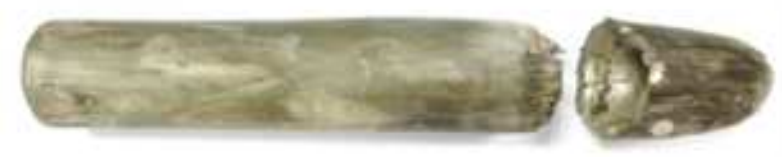

Fig. 11. Configuration E, Post-test penetrator view.

\section{Conclusion}

A lot of achievements have been reached at the end of this one year MCM-ITP project. The main objective was quite ambitious: to manage to design a warhead penetrator using lattice structures in order to reduce its mass and guarantee at the same time its mechanical strength (survivability) and its performances or even improve them. 
Some challenges had to be tackled such as the determination of an alternative geometry for the lattice and also an alternative material (17-4PH instead of $316 \mathrm{~L}$ ). Those two points were mandatory in order to guarantee the survivability of the penetrator.

Regarding the warhead performance predictions, the main challenge was to define a homogenised material law as it was not possible to represent, in $3 \mathrm{D}$, all lattices for the complete warhead.

All numerical simulations have been performed before experiments, so no artificial tuning nor modification within the model were made and they showed good correlation with the perforation tests.

The small scale penetrators and the experiments have been realised in less than 6 weeks, which given the technical challenges and the innovative nature of the project was not an easy thing.

The results obtained are really conclusive and promising. A Lattice based penetrating warhead showed good behaviour and survived the impact for different arrival conditions especially at supersonic speed $(450 \mathrm{~m} / \mathrm{s}$ to $720 \mathrm{~m} / \mathrm{s})$ and relatively high angle of impact $\left(15^{\circ}\right)$.

In 6 of the 7 firing tests, the full perforation of the target is obtained.

The average mass saving is about $15 \% \quad(30 \%$ theoretically) using lattices compared to a full solid warhead.

Some points have to be improved particularly regarding manufacturing, for example to take into account as soon as possible, in the design process, the powder elimination path.

This study could be extended to other domains like the evaluation of the fragmentation of a lattice based warhead casing and at the same time assess the blast effects in order to determine the benefits using lattice structures and their impact on the confinement.

A test campaign, at small scale level could be performed in order to compare numerical modelling to experiments.
Acknowledgements: This work was funded by the FrenchUK Materials and Components for Missiles-Innovation and Technology Partnership (MCM ITP) research programme.

\section{References}

1. Lars Olovsson, Jérôme Limido, Jean-Luc Lacome, Arve Grønsund Hanssen, Jacques Petit, Modeling fragmentation with new high order finite element technology and node splitting, EPJ Web of Conferences 9404050 DOI: 10.1051/epjconf/20159404050 (2015)

2. Ozdemir, Zuhal \& Tyas, Andrew \& Goodall, Russell \& Askes, Harm, Energy absorption in lattice structures in dynamics: Nonlinear FE simulations. International Journal of Impact Engineering. 102. 10.1016/j.ijimpeng.2016.11.016 (2016)

3. Thomas Tancogne-Dejean, Adriaan B. Spierings, Dirk Mohr, Additively-manufactured metallic micro-lattice materials for high specific energy absorption under static and dynamic loading, In Acta Materialia, Volume 116, Pages 14-28, ISSN 1359-6454, https://doi.org/10.1016/j.actamat.2016.05.054 (2016)

4. J. Limido, M. Trabia, S. Roy, B. OToole, R. Jennings, W. Mindle, M. Pena, E. Daykin, R. Hixson, M. Matthes, Modeling of Hypervelocity Impact Experiments Using Gamma-SPH Technique, ASME 2017 Pressure Vessels and Piping Conference PVP2017, Waikoloa, Hawaii, July (2017)

5. Holmquist, T. J.; Johnson, G. R.; Cook, W. H. A Computational Constitutive Model For Concrete Subjected To Large Strains, High Strain Rates, and High Pressures. Intl Symp on Ballistics 1993, 14, 591-600 (1993)

6. Hansson H., Warhead penetration in concrete protective structures, KTH Sweden (2011) 